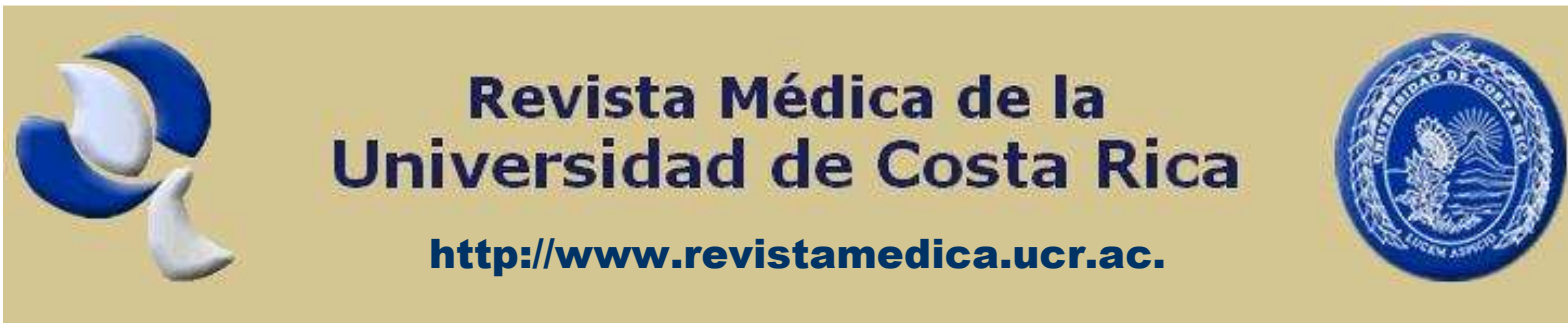

Conversatorio

\title{
¿El porqué de las Ciencias Médicas?
}

\section{Jaramillo Antillón, Juan}

Profesor emérito de la Escuela de Medicina de la Universidad de Costa Rica. San Pedro, Costa Rica.

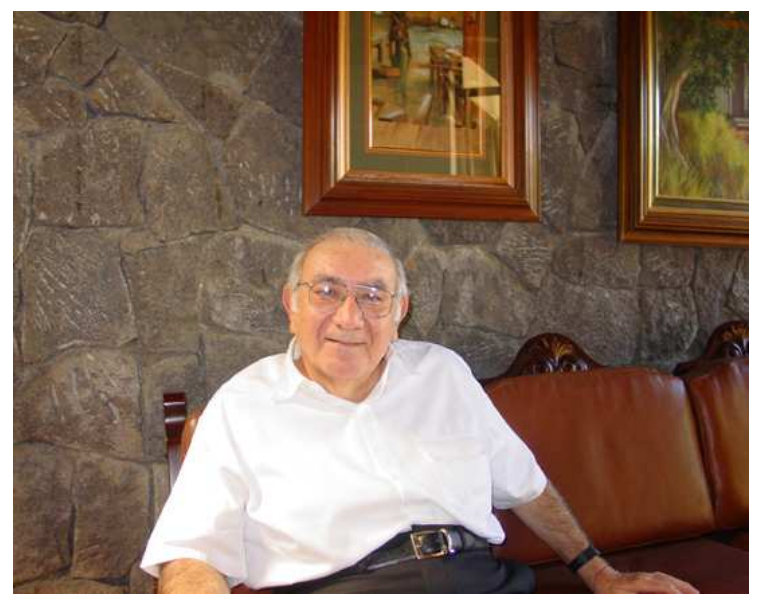

CONVERSACIONES CON EL DR. JUAN JARAMILLO ANTILLON

Recibido: Diciembre 2007. Aceptado: Febrero 2008. Publicado: Marzo 2008.

Pregunta $(\mathrm{P})$ : ¿Qué importancia tiene la medicina como profesión en la sociedad? Respuesta(R): Si usted le pregunta a un político, un economista, un educador eso. Estos le contestaran que la suya es la más importante y darán sus razones para ello.

Sin embargo, ninguno puede señalar que su profesión o ciencia es la única que acompaña y sobre todo protege al ser humano durante toda su vida, desde antes de su nacimiento y hasta su muerte.

$\mathrm{P}$ : ¿Acláreme esto? R: 1- Desde antes de nacer, protegemos a los niños contra enfermedades congénitas en la columna por ejemplo proporcionando ácido fólico entre otros medicamentos.

Diagnosticamos in-útero lesiones congénitas e incluso reparamos muchas de ellas precozmente con cirugía como los quistes pulmonares y otras lesiones. 2- Durante el embarazo de la madre controlamos la salud de ambos. 3Durante el parto, atendemos a ambos. 4- Inmediatamente después del 
nacimiento protegemos la salud de ambos y con la prueba del Tamisaje del talón al niño le diagnosticamos y tratamos precozmente más de 24 enfermedades. 5- Durante toda la vida de las personas la medicina les ayuda a prevenir enfermedades 0

a recuperar la salud, y finalmente 6- Les ayuda a morir de la mejor forma posible.

P: ¿Pero, usted incluye medidas preventivas en el concepto de la medicina?, ¿es eso correcto? R: Por supuesto. La medicina es el arte y la ciencia empleados para conservar la salud y diagnosticar y tratar las enfermedades. El problema del por qué los médicos perdieron por siglos su papel en el campo de los cuidados de la salud, se debió a que ellos y las escuelas de medicina se dedicaron sobre todo a conocer y tratar las enfermedades únicamente, olvidando las enseñanzas de Hipócrates para quien la medicina englobaba el cuidado de la salud. Recordemos su famosa frase Primun non nocere, primero no hacer daño, la salud y la vida del enfermo son la primera consideración de un médico. De hecho esta expresión, constituye el primer código de ética que gobierna la conducta de los médicos desde los tiempos hipocráticos.

$P: ¿$ Trasladada al presente que significa esto? R: Que el médico debe tener evidencia clínica basada en una amplia experiencia y estudios, de la efectividad de una terapia (médica o quirúrgica) antes de recomendar un tratamiento a su paciente.

P: ¿Puede entonces un medico garantizar que siempre se obtendrán buenos resultados con su tratamiento? R: Por supuesto que no, la evolución de la ciencia y la medicina que forma parte de esta, demuestra que la certeza es incompatible con la ciencia y que esta vive de verdades relativas.

Justamente en eso estriba la posibilidad del progreso científico. Por eso la medicina no es una ciencia exacta y de hecho el único dogma aceptado en medicina, es que no hay dogmas ni verdades absolutas en ella. Esa es la realidad por la cual está siempre en renovación continua a diferencia de otros campos del saber humano.

$\mathrm{P}$ : ¿Según eso lo que ayer era correcto en medicina hoy puede no serlo? R: Si, debido a que un nuevo conocimiento sobre las causas de una enfermedad nos hace modificar el tratamiento por otro nuevo más avanzado para beneficio del ser humano. Con el agravante que cada día aparecen nuevos conocimientos en medicina que dan lugar a la aparición de nuevos medicamentos o nuevas tecnologías que están encareciendo los costos a cifras imposibles de pagar por las personas e incluso por los Seguros Sociales.

P: ¿Entonces la medicina no es una ciencia exacta? R: La medicina es a la vez que una ciencia, porque incluso emplea el método científico, en muchos momentos, un arte de conjeturas, destrezas e hipótesis en renovación continúa. Cada paciente que se atiende o cada enfermo que se opera, es un ser diferente, y no puede por ello generalizarse las conductas o seguir siempre los protocolos establecidos para cada enfermedad, sino que deben individualizarse, pues estamos como decía Hipócrates ante enfermos más que ante enfermedades. 
P: ¿Entonces la posibilidad de error siempre está presente en medicina? R: Los estudiantes de medicina y los médicos jóvenes deben tener muy claro que cada caso médico tiene sus singularidades, y aunque muchos pueden ser resueltos mediante acciones 0 procedimientos estandarizados, otros requieren de soluciones distintas; en ocasiones la diferencia es muy sutil y en otras clara y evidente.

P: ¿Usted cree que en la actualidad a los estudiantes de medicina se les advierte sobre eso? R: Creo que no. Cuando los médicos inician la práctica de su profesión no se les advierten los riesgos de ella, peligros que tienen que ver con la salud y la vida de los enfermos que tratan. Un error o una complicación inesperada en la atención de un paciente, puede dar lugar a una acusación de "mala práctica médica" que puede afectar el prestigio e interferir en su libertad, economía y hasta en su salud. De tal forma que los médicos recién graduados deben conocer de estos problemas cuando inician

sus actividades profesionales y tener presente las normas y reglamentos sobre los cuales puede atender al paciente.

P: ¿Qué aconsejaría usted a los estudiantes recién graduados para evitar estos peligros? R: 1- Prepararse adecuadamente en cuanto a conocimientos teóricos y disponer de una práctica intensa en su campo. 2Estar permanentemente actualizado. 3Saber escoger los casos que puede tratar. 4- Ante un caso difícil obtener apoyo de un médico con experiencia o referir el caso. 5- Contar con los medios técnicos de laboratorio y gabinete adecuados para lograr un diagnóstico o tratamiento adecuado. 6- Exigir a la institución donde trabaja que le proporcione los recursos mínimos suficientes para laborar con suficiencia. 7-Siempre estar a la defensiva, ya que el médico, como nos enseñó Hipócrates aprende más del error que del éxito. Si no sigue estas medidas, el médico puede convertirse en un factor de riesgo para el enfermo.

$\mathrm{P}$ : ¿Usted tiene alguna norma en la relación médico-paciente? $\mathrm{R}$ : $\mathrm{Si}$, Para evitar malas interpretaciones, el médico desde ningún punto de vista debe prometer al paciente o a su familia buenos resultados en su intervención cuando le consulta por una enfermedad seria. Debe eso sí, ofrecer proporcionar los mejores medios posibles en cuanto a su preparación científica y el empleo de la tecnología adecuada, para ver si logra la cura del enfermo.

P: ¿Entonces la medicina para su buen ejercicio tiene requisitos muy difíciles de llenar? R: Desgraciadamente sí, la gente cree que nosotros somos dioses y no meros mortales y que no estamos sujetos al error o a complicaciones inesperadas. De hecho cuando un paciente grave es curado por nosotros se dice que se debió a un milagro, y cuando no se curan nos echan la responsabilidad en muchos casos aún sin tenerla. Por esa razón yo digo lo siguiente: La enfermedad como el error y las complicaciones en toda actividad, forman parte de la vivencia del ser humano. Los buenos médicos, al igual que los seres superiores, no son los que no se equivocan, sino los que se equivocan menos.

La medicina no sólo debe estar ejercida por médicos con buena preparación académica, sino, además, con buenas

Revista electrónica publicada por el Departamento de Farmacología de la Escuela de Medicina de la Universidad de Costa Rica, 2060 San José, Costa Rica. ${ }^{\circledR}$ All rights reserved. 
bases morales como honestidad $y$ espíritu de servicio. Un médico ético, sin buena preparación académica, es un serio problema para los cuidados de la salud de la población.

Un médico bien preparado científicamente, sin ética, es un sinvergüenza que desprestigia a la profesión y debe ser separado. Finalmente, un médico con mala preparación y sin ética es un peligro público

y debe ser eliminado como profesional.

$P$ : ¿Esta gran cantidad de escuelas de medicina sin Acreditar, estarán produciendo estos tipos de médicos? R: Lamentablemente creo que es culpa del Gobierno y del Ministerio de Educación no tener un buen sistema de Evaluación y Acreditación de escuelas de medicina. Ni siquiera el SINAES tiene específicamente un buen programa para Escuelas de Medicina, aunque por lo menos investiga y obliga a mejorar deficiencias en los recursos para la enseñanza. Por eso aplaudo el intento que hace el Colegio de Médicos de tratar de acreditar "voluntariamente" a los médicos para el desarrollo de su profesión.

$\mathrm{P}$ : ¿Porqué se exige tanto a los profesionales en medicina y no lo mismo a otros profesionales. $\mathrm{R}$ : Porque tratamos con la salud y la vida de las personas, algo que ninguna profesión toca. De hecho, no hay ninguna de ellas, ni siquiera el sacerdocio, donde la persona se confiese tan abiertamente en la consulta con su médico y llegue al extremo de poner su vida en las manos de este profesional, aceptando todo tipo de decisiones y tratamiento e incluso operaciones donde puede perder la vida, tal es la confianza que tienen en ellos. De ahí que la sociedad exija más requisitos al médico que a otros profesionales.

$\mathrm{P}$ : ¿Cuál es su definición de salud? R: Hay muchas, la más simple es decir que "es la ausencia de enfermedad". La OMS (Organización Mundial de la salud) afirma que la salud significa " Un completo estado de bienestar físico, mental y social del ser humano", aunque esto para mi es utópico, ya que muy difícil saber si una persona está sana ya que muchas enfermedades congénitas o adquiridas se declaran solo con los años $y$ por otro lado hay personas que estando sanas viven preocupadas y ansiosas por su futuro y eso no las deja ser felices, mientras que otras incluso minusválidos se sienten felices de poder vivir a pesar de su enfermedad. Lo que sí está claro es que lograr la salud de una persona o una población no solo es un fin en sí mismo, sino

también un prerrequisito para alcanzar un buen desarrollo educacional, social y económico.

P: ¿Porqué, la gente no le da importancia a estar saludables? R: Porque precisamente no conocen la importancia de la salud, ya que es como el aire: no se ve, no se siente, no huele y solamente en su ausencia y al enfermarnos nos damos cuenta de la falta de ella. Aun más, es gracias a ella que crecemos, podemos jugar, estudiar, trabajar, disfrutar de la vida y desenvolvernos adecuadamente en la sociedad y cumplir las metas deseadas.

$P$ : ¿Según usted, la conservación de la salud del ser humano, es el concepto clave de la medicina y su meta principal ahora y en el futuro? R: Si, Pero, obtener salud no es solo 
responsabilidad de los médicos y de la medicina, sino que lograr esto es problema de todos ya que la salud de la población depende de muchos factores algunos de ellos heredados y otros de riesgo o adquiridos.

P: ¿Cuáles seria estos? R: Una buena herencia familiar, adecuada alimentación en la infancia cuidados y ejemplos de los padres para adquirir buenas costumbres, no es posible que los niños no fumen ni beban si ven a sus padres hacer esto. Se les deben dar buenas normas dietéticas para evitar obesidad, hacer ejercicios, tomar los problemas con calma y tratar de resolverlos con el menor estrés posible. Sexo seguro, buenas relaciones familiares y con la comunidad, que la persona tenga los recursos económicos mínimos para vivir y educarse, evitar riesgos (la velocidad por ejemplo). Todo esto puede llevar a una persona a una vejez relativamente sana y que

logré con ello no más años de vida, sino darle más calidad de vida a sus años. Por otro lado, aceptamos que pese a lo señalado existen otros factores inesperados o el llamado azar, como son un accidente inesperado o una violencia criminal que puede traumatizar o herir o hasta matar a una persona sin que podamos previamente intervenir para evitarlo.

P: ¿Entonces hemos dejado de ver la obtención de la salud solo como un fenómeno biológico? $\mathrm{R}$ : $\mathrm{Si}$, ahora aceptamos una íntima relación con la educación que tienen los padres y el resto de la familia, los estilos de vida, el medio donde viven las personas y los recursos que poseen.
P: ¿Entonces la salud no se le puede imponer a una población o a una persona? R: Exactamente, usted ha dado en el clavo. Las instituciones del gobierno y los médicos pueden ofrecer cuidados para la protección de ella a las personas, y además, servicios para recuperar o rehabilitar a esta cuando alguien se enferma. "pero es cada persona o si se trata de niños, son los padres los que han de decidir, con base a la educación recibida, si aceptan los consejos y las medidas de prevención y eliminan los malos hábitos y los factores de riesgo de su vida".

P: ¿De acuerdo con eso los padres deberían ser los primeros promotores de salud? R: Exactamente, de ahí la importancia de que las autoridades de la salud proporcionen educación para la salud y prevención a todos los hogares y a las comunidades.

$P: \quad ¿ E s t o s$ conceptos se están enseñando en las escuelas de medicina actualmente? $\mathrm{R}$ : $\mathrm{Si}$, aunque como le dije, por siglos fueron olvidados.

$P: ~ ¿ E s t o s$ son para usted los fines de la medicina? R: Si en parte. En realidad los fines de la medicina no han cambiado desde los tiempos hipocráticos, donde se sentaron las bases de la medicina científica hace 2400 años y que a mi manera de ver no se modificaran en los próximos años.

P: ¿Pero ha habido muchos cambios en la medicina? R: Lo que cambia son "los medios" para obtener esos fines. "Los recursos" para tener acceso a esos medios y además, la aparición de nuevas enfermedades o riesgos para la salud que la civilización moderna nos ha traído como secuela de los avances

Revista electrónica publicada por el Departamento de Farmacología de la Escuela de Medicina de la Universidad de Costa Rica, 2060 San José, Costa Rica. ${ }^{\circledR}$ All rights reserved. 
tecnológicos y sociales. Como usted bien dice. De hecho a través de los siglos se han producido extraordinarios cambios en el campo de la medicina en su lucha para evitar y tratar la

enfermedad o para recuperar la salud, incluyendo los transplantes y el empleo de genes, todo ello gracias al desarrollo de nuevos conocimientos de como se producen las enfermedades, por las nuevas vacunas, medicamentos de diversos tipos, nuevas tecnologías diagnosticas y terapéuticas que ahora nos permiten tratar $u$ operar cualquier parte del cuerpo. Pero desde la antigüedad Hipócrates y su escuela nos habían aconsejado sabiamente sobre cómo conservar la salud y sin embargo insisto que por siglos menospreciamos eso.

Hipócrates decía que en parte, las enfermedades eran causadas por la influencia nociva proveniente del medio ambiente donde se vivía o del medio social que rodeaba a las personas, como era la pobreza, la mala educación, la insalubridad, la mala alimentación, así como abusos en comer, el exceso de sexo, de licor, de drogas, las aguas insalubres en los alrededores o falta de agua limpia para tomar, los accidentes y la violencia. Desde entonces Hipócrates preconizaba enseñar a la gente esos factores de riesgo existentes con el fin de evitar la enfermedad.

Dos mil años después se comenzó a descubrir que existían entre las miles de bacterias, parásitos, hongos y virus en la naturaleza no patógenos, algunas decenas que si provocaban enfermedades. Aparecieron las vacunas y los antibióticos y pese a ello continuó la enfermedad afectando a las poblaciones.

Se llegó por fin a aceptar en las escuelas de medicina los conceptos hipocráticos de que el médico no sólo debe curar, sino aprender también a evitar que las personas se enfermen mediante consejos y medidas preventivas.

P: ¿Entonces el fenómeno de estar saludable es algo complejo? $\mathrm{R}$ : $\mathrm{Si}$, porque con el tiempo llegamos a entender que la salud depende de un equilibrio entre: A) Los factores internos defensivos congénitos o adquiridos del cuerpo humano y $\mathrm{B})$ Los riesgos externos del ambiente de diferente tipo que existen y a los que todos estamos expuestos (virus, bacterias, parásitos, accidentes, violencia, etc.).

"La amistad está basada en la tolerancia"

Juan Jaramillo Antillón 